(CASE REPORT)

\title{
Hard-to-heal wounds: A new biofilm treatment with a novel desiccant
}

\author{
Mariana Peroni ${ }^{1}$, Renzo Girardello ${ }^{2}$, Ornella Pancheri ${ }^{3}$, Stefano Bonvini ${ }^{4}$ and Giampietro Bertasi $5,{ }^{*}$ \\ ${ }^{1}$ U.O. Geriatry - Diabetology, Santa Maria del Carmine Hospital, Rovereto, Italy. \\ ${ }^{2}$ U.O. Geriatry - Diabetology, Santa Maria del Carmine Hospital, Rovereto, Italy. \\ 3 U.O Vascular Surgery, Santa Maria del Carmine Hospital, Rovereto, Italy. \\ ${ }^{4}$ U.O Vascular Surgery, Santa Maria del Carmine Hospital, Rovereto, Italy. \\ ${ }^{5}$ Biotechnologies Department, University of Padua, Italy.
}

Magna Scientia Advanced Biology and Pharmacy, 2021, 03(01), 058-063

Publication history: Received on 23 July 2021; revised on 28 August 2021; accepted on 30 August 2021

Article DOI: https://doi.org/10.30574/msabp.2021.3.1.0036

\begin{abstract}
Biofilms are slow-growing communities of multiple strains of bacteria that resist both innate immunemechanisms as well as antibiotics [1] [16] [17]. They also contain extracellular DNA (bacterial or host origin), polysaccharides, and proteins that formdense matrix is resistant to the host's innate immune response [18] [19].
\end{abstract}

Keywords: Dissecant; Biofilm; Chronic Wound; Wound Bed Preparation (WBP)

\section{Introduction}

Biofilms are believed to occur in $60-100 \%$ of chronic wounds [2] [5]. The World Union of Wound Healing Societies released a position statement that they believe cliniciansshould assume that all chronic wounds that have failed to heal under standard of care contain a biofilm [3] [20].

Biofilms are a self-feeding barrier:

- With resistance to host's innate immune response

- With resistance to antibiotics due to slow growth rate

○ The mechanism for antibiotic function happens during replication, therefore low replication, low antibiotic activity.

- $\quad$ Secrete glycolipids that disrupt signaling as well as proteolytic enzymes that attack ECM proteins Chronic skin wounds represent a major health problem and financial burden [21].

\section{Biofilm}

There are many factors in biofilms that contribute to inhibition of wound healing. Data suggest that chronic wounds are trapped in the acute inflammatory phase of healing,which amplifies over time [8]. Dynamic Reciprocity (DR) is out of balance [9] [28]. DR is an ongoing, bidirectional interaction between cells and their surrounding microenvironment (including ECM), it plays critical role in biochemical, biophysical and cellular responses that regulate tissue regenerative responses. DR between cells and Extracellular matrix (ECM) [10].

\footnotetext{
${ }^{*}$ Corresponding author: Giampietro Bertasi

Biotechnologies Department, University of Padua, Italy. 
Cells synthesize ECM components, and degrade and remodel ECM, the latter events occurringthrough the production and regulation of matrix metalloproteases (MMPs) and other enzymes.

The ECM regulates cellular tension and polarity, differentiation, migration, proliferation, and survival.

The ECM consists of collagen, elastin, multidomain glycoproteins (i.e., fibronectin), and proteoglycans and glycosaminoglycans.

The composition of the ECM varies by tissue and by state of the tissue (i.e., intact adult tissue, healing wound, etc.)

Due to their continued persistence, biofilm infections cause more damage and greater inflammatory

responses than the corresponding infections caused by planktonic bacteria [6] [7] [22] [23].

The biofilm matrix, composed of proteins, DNA and sugars, is called Extracellular Polymer Substance, or EPS1-3 The biofilm is difficult to eradicate because it is resistant to antimicrobial therapies [24] [25]. and tothe host's immune system [2] [3].

To effectively eradicate the biofilm and promote healing, an antimicrobial must be able to penetrate the EPS and attack the bacteria inside with a prolonged action that prevents the biofilm from reforming [26] [27].

P-toluensulfonic acid is used for the topical/local treatment of skin areas at high risk of bacterial development thanks to its ability to remove bacterial biofilm with a physical mechanism of action dependent on the dehydrating nature of the product and independent of the bacterial species present.

Wound Bed Preparation was performed solely as surgical debridment [4].

Dessicating agent was applied and distributed with a gloved finger on the wound bed and approximately $1 \mathrm{~cm}$ margin of surrounding healthy skin and had remained on the wound bed for 10-15 seconds. The wound has been rinsed with wet (saline) sterile gauze and medicated as usual.

This procedure has been repeated at 1 week interval until the wound bed had progressed up to $100 \%$ granulation, wound healing to spontaneous reepithelization or skin graft or ADM.

\section{Clinic}

\#1 - Man, 56 years old

Chronic ulcer in type 2 diabetic patient with kidney transplant

Healing after 4 p-toluensulfonic acid applications

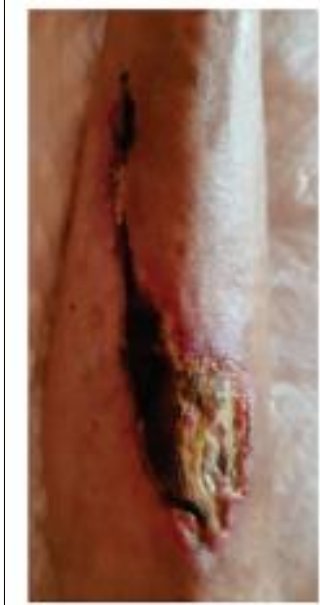

Day 0

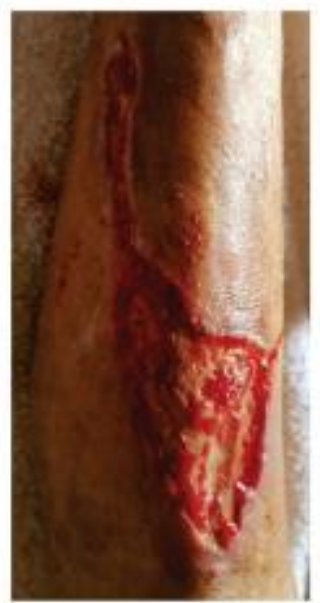

Day 14

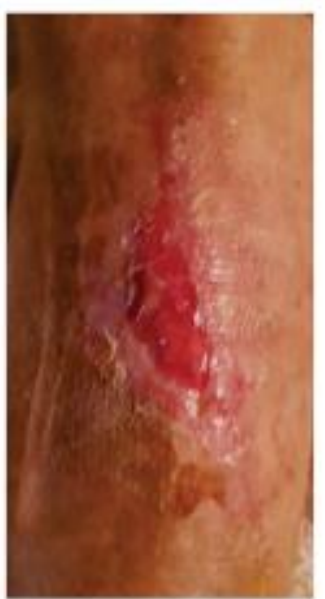

Day 28

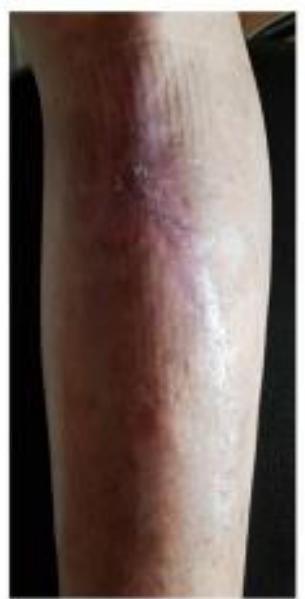

Day 40

Courtesy of G. Bertas 
\#2 - Man, 47 years old

Necrosis in type 2 diabetes wounds

1 p-toluensulfonic acid applications after surgical debridment

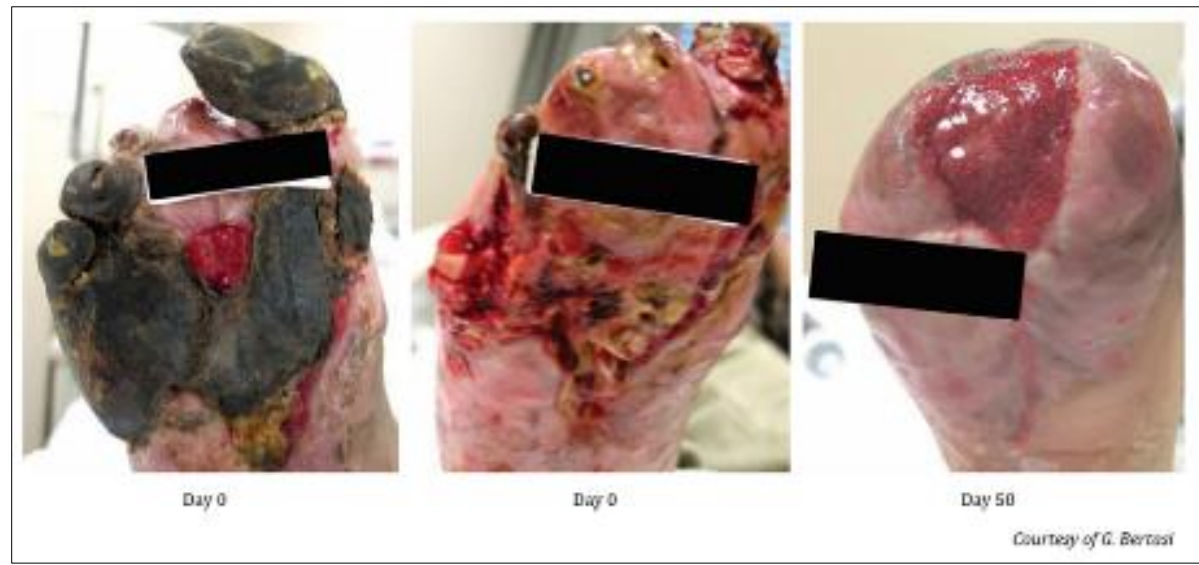

\#3 - Woman, 86 years old

Chronic ulcer in type 2 diabetes

Healing after 1 p-toluensulfonic acid
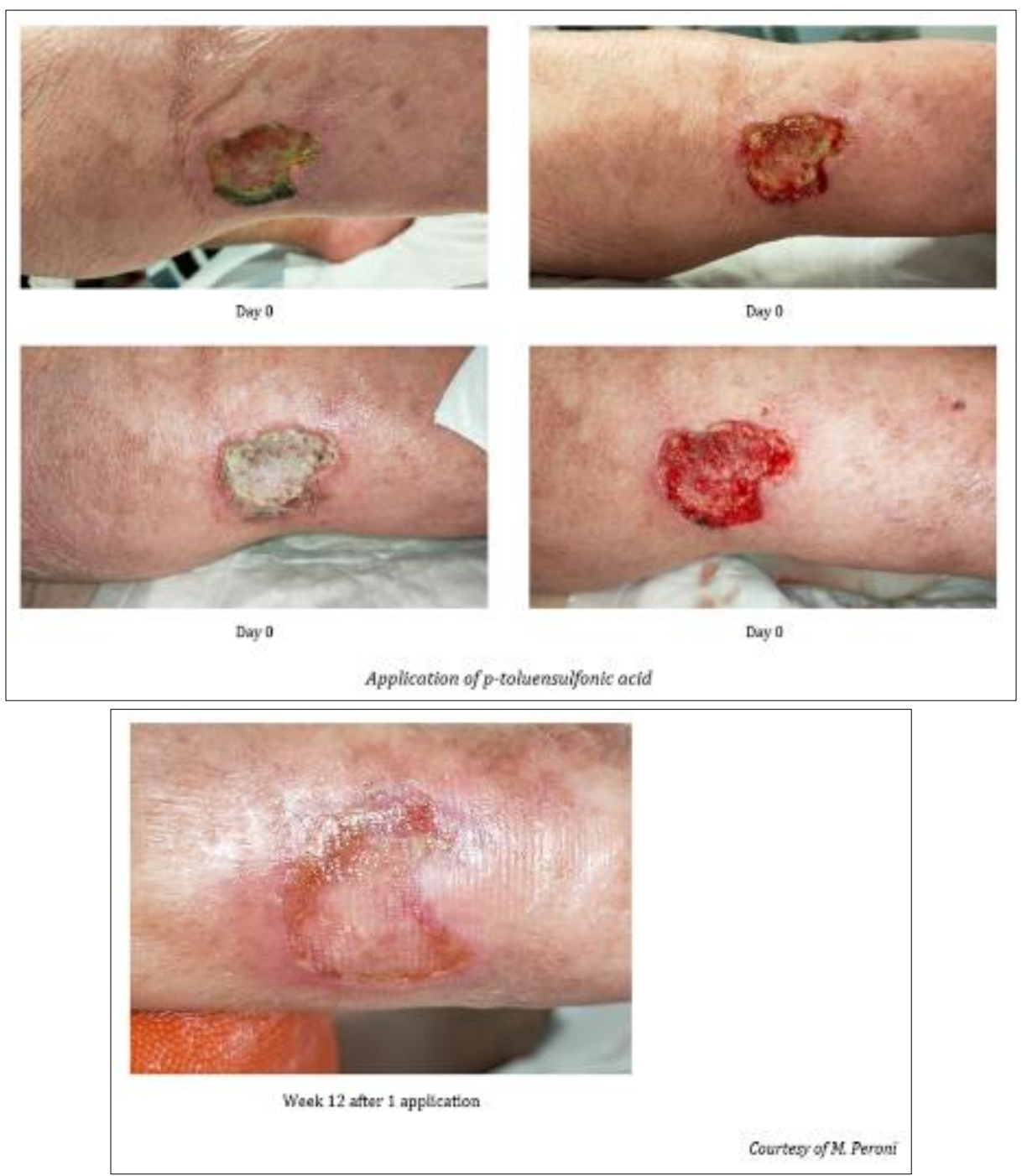
\#4 - Woman, 62 years old

Type 2 diabetes - Neuropathy - Infection

Healing after 5 p-toluensulfonic acid applications and ADM grafted

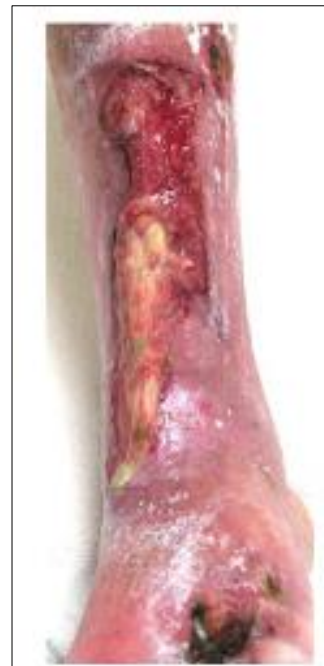

Day 0

Granulation after WBP and 5 p-toluensulfonic acid app.

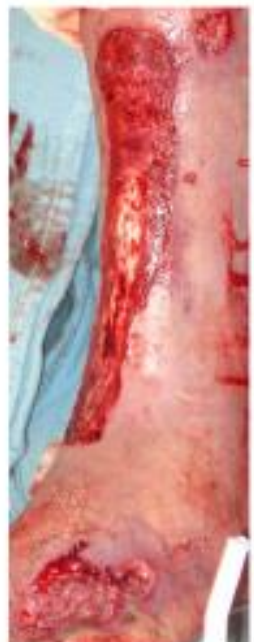

Day 30

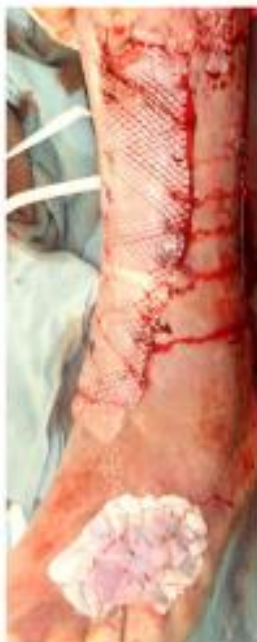

Day 30

$A D M$ grofted

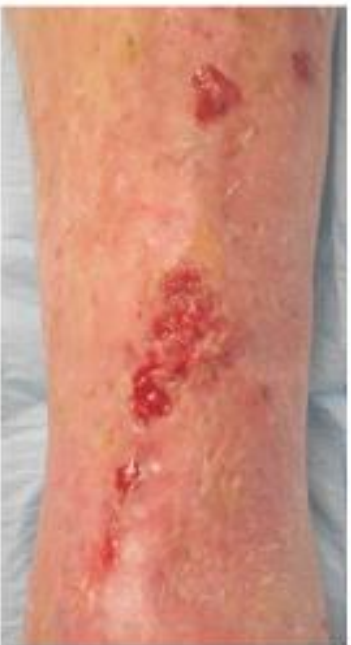

Week 15

Healing ofter 15 w6eks

\#5 - Woman, 86 years old

Type 2 diabetes - Neuropathy e Vasculopathy (macro e micro)

Healing after 4 p-toluensulfonic acid applications and Split Skin Graft

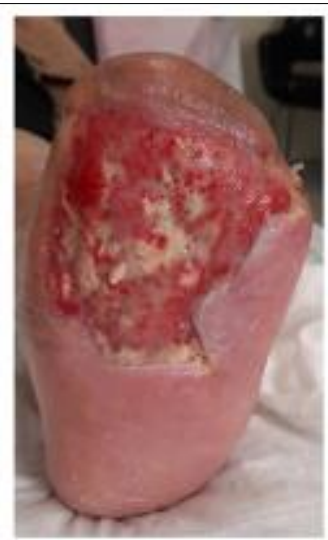

Das 0

Appication of p-toluensulfonic octd

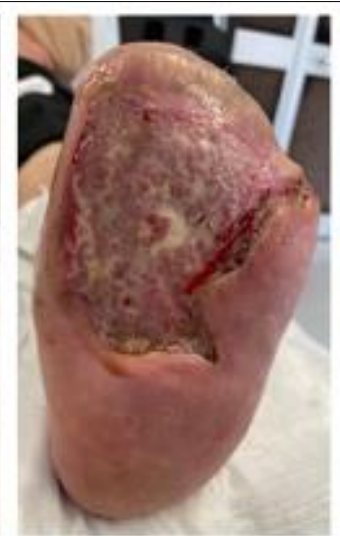

Day 0

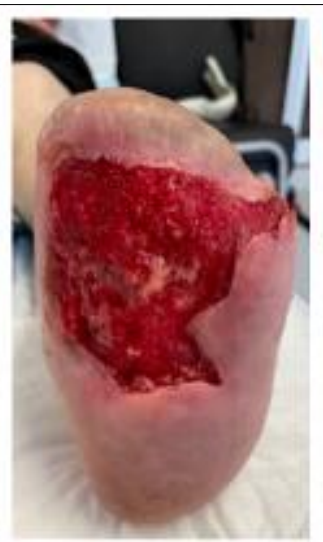

Weeks

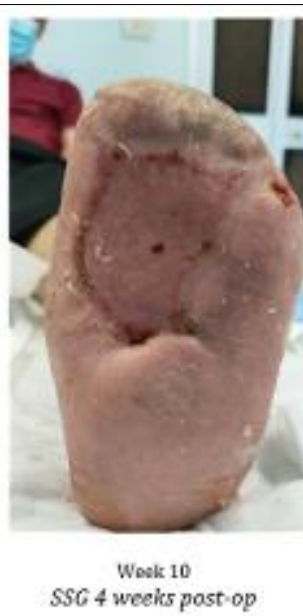

$S S C 4$ weeks post-op

Courtey of M. Psronie Q Pancheri

\section{Conclusion}

Overall, p-toluensulfonic acid reports a remarkable anti-biofilm effect and promote healing. Dissecating agent treatment appears to restart the healing process of chronic ulcers.

\section{Compliance with ethical standards}

\section{Acknowledgments}

The Authors acknowledge the p-toluensulfonic acid Italian producer for providing the material for the cases described. 


\section{Disclosure of conflict of interest}

The Authors have no actual or potential conflict of interest in relation to this paper.

\section{Statement of informed consent}

Informed consent was obtained from all individual included in cases study.

\section{References}

[1] Attinger and Wolcott. Biofilm-based Healthcare-associated infections" Donelli (ed); Position Document from World Union of Wound Healing Societies. 2016.

[2] Biofilms Made Easy. Phillips Pl. et al. Wounds International 2010; The prevalence of biofilms in chronic wounds: a systematic review and meta-analysis of published data.

[3] Percival SL, Int Wound J. Consensus guidelines for the diagnosis and treatment of biofilm in chronic non-healing wounds. 2019.

[4] RD Wolcott, JP Kennedy, SE Dowd. Journal of Wound Care, Vol. 1 B, No. 3, February 2009; Regular debridement is the main tool for maintaining a healthy wound bed in most chronic.

[5] A Omar, JB Wright, G Schultz, R Burrell, P Nadworny. Microbial Biofilms and Chronic Wounds.

[6] C Attinger, R Wolcott. Clinically addressing biofilm in chronic wounds, Adv Wound Care (New Rochelle). 2012 Jun; 1(3): 127-132.

[7] Biofilm-based healthcare-associated infections. Vol. II; Spinger.

[8] The biofilm in chronic wounds: World Union of WUWHS - Congress in Florence, Italy. Position document. Wound International. 2016.

[9] GS Schults, JM Davidson, RS Kisner, P Bornstein, IM Herman. Dynamic reciprocity in the wound micromovement; Wound Repair Regen. Mar 2011; 19(2): 134-148.

[10] Khan Academy. The extracellular matrix and cell walls, AP.BIO: ENE-2 (EU); ENE-2 (LO); ENE-2.D.1 (EK).

[11] De La Fuente-Nunez C, Reffuveille F, Fernández L, Hancock RE. Bacterial biofilm development as a multicellular adaptation: antibiotic resistance and new therapeutic strategies. Curr. Opin. Microbiol. 2013; 16: 580-589.

[12] Kostakioti M, Hadjifrangiskou M, Hultgren SJ. Bacterial biofilms: development, dispersal, and therapeutic strategies in the dawn of the postantibiotic era. Cold Spring Harbor Perspect. Med. 2013; 3: a010306.

[13] Lynch AS, Robertson GT. Bacterial and fungal biofilm infections. Annu. Rev. Med. 2018; 59: 415-428.

[14] Flemming HC, Wingender J. The biofilm matrix. Nat. Rev. microbiol. 2010; 8: 623-633.

[15] Gregory et al. Consensus guidelines for the identification and treatment of biofilms in chromic nonhealing wounds. 2016.

[16] De La Fuente-Nunez C, Reffuveille F, Fernández L, Hancock RE. Bacterial biofilm development as a multicellular adaptation: antibiotic resistance and new therapeutic strategies. Curr. Opin. Microbiol. 2013; 16: 580-589.

[17] Kostakioti M, Hadjifrangiskou M, Hultgren SJ. Bacterial biofilms: development, dispersal, and therapeutic strategies in the dawn of the postantibiotic era. Cold Spring Harbor Perspect. Med. 2013; 3: a010306.

[18] Lynch AS, Robertson GT. Bacterial and fungal biofilm infections. Annu. Rev. Med. 2018; 59: 415-428.

[19] Flemming HC, Wingender J. The biofilm matrix. Nat. Rev. microbiol. 2010; 8: 623-633.

[20] Gregory et al. Consensus guidelines for the identification and treatment of biofilms in chromic nonhealing wounds. 2016.

[21] Batoni G, Maisetta G, Esin S. Antimicrobial peptides and their interaction with biofilms of medically relevant bacteria. Biochimica. Biophys. Acta (BBA) Biomembranes. 2016; 1858: 1044-1060.

[22] Lebeaux D, Ghigo JM, Beloin C. Biofilm-related infections: bridging the gap between clinical management and fundamental aspects of recalcitrance toward antibiotics. Microbiol. Mol. Biol. Rev. 2014; 78: 510-543. 
[23] Donlan RM, Costerton JW. Biofilms: survival mechanisms of clinically relevant microorganisms. Clin. Microbiol. Rev. 2002; 15: 167-193.

[24] Bridier A, Briandet R, Thomas V, Dubois-Brissonnet F. Resistance of bacterial biofilms to disinfectants: a review. Biofouling. 2011; 27: 1017-1032.

Biofilms Made Easy. Phillips Pl. et al. Wounds International 2010The prevalence of biofilms in chronic wounds: a systematic review and meta-analysis of published data.

[25] Percival SL et al. Int Wound J2019 Consensus guidlines for the diagnosis and treatment of biofilms in choronic non healing wounds.

[26] Romling U, Balsalobre C. Biofilm infections, their resilience to therapy and innovative treatment strategies. J.Int. Med. 2012; 272: 541-561.

[27] WUWHS Position document, Advances in wound care: the triangle od wound assessment. 